\title{
Are we prepared for emerging and re-emerging diseases? Experience and lessons from epidemics that occurred in Tanzania during the last five decades
}

\author{
ESRON D. KARIMURIBO ${ }^{1 *}$, LEONARD E.G. MBOERA ${ }^{2}$, ERASTO MBUGI ${ }^{3}$, AZMA SIMBA ${ }^{4}$, FREDRICK M. \\ KIVARIA ${ }^{5}$, PETER MMBUJI ${ }^{4}$ and MARK M. RWEYEMAMU ${ }^{1}$ \\ ${ }^{1}$ Southern African Centre for Infectious Disease Surveillance, Sokoine University of Agriculture, Morogoro, \\ Tanzania \\ ${ }^{2}$ National Institute for Medical Research, Dar es Salaam, Tanzania \\ ${ }^{3}$ Muhimbili University of Allied and Health Sciences, Dar es Salaam, Tanzania \\ ${ }^{4}$ Ministry of Health and Social Welfare, Dar es Salaam, Tanzania \\ ${ }^{5}$ Ministry of Livestock and Fisheries Development, Dar es Salaam, Tanzania
}

\begin{abstract}
This paper reviews preparedness for containing and controlling emerging and re-emerging diseases drawing lessons from disease events that occurred in animal and human populations in the last five decades (1961-2011). A comprehensive analysis based on retrieval and analysis of grey and published literature as well as reported cases was carried out to document type and trend of occurrence of emerging and re-emerging infectious diseases in different parts of Tanzania. Overall, the majority of diseases reported in the country were viral in nature followed by bacterial diseases. The trend for the occurrence shows a number of new emerging diseases as well as re-occurrence of old diseases in both animal (domestic and wild) and human populations. In humans, the major disease epidemics reported in the last five decades include cholera, influenza A H1N1, plague and rubella. In animals, the major epidemic diseases reported were Contagious Bovine Pleuropneumonia, Contagious Caprine Pleuropneumonia, Peste des petits ruminants and Giraffe Ear and Skin Diseases. Some epidemics have been reported in both human and animal populations including Rift Valley fever and anthrax. The emergence of the 'fit-for purpose' approaches and technologies such as the discipline of One Health, use of participatory epidemiology and disease surveillance and mobile technologies offers opportunity for optimal use of limited resources to improve early detection, diagnosis and response to disease events and consequently reduced impact of such diseases in animal and human populations.
\end{abstract}

Keywords: emerging and re-emerging infectious diseases, outbreak, trends, preparedness, Tanzania

\section{Introduction}

Emerging and re-emerging infectious diseases (EIDs) are those infections that have newly appeared in a population or have existed but are rapidly increasing in incidence or geographical range (Morse, 1995). The occurrence of EIDs may be explained by ecological, environmental or demographic factors that place people at increased contact with a previously unfamiliar microbe or its natural host or promote dissemination. The impact of EIDs is immense as indicated by morbidity and mortality in animal and human populations. King et al. (2006) reported that infectious diseases are responsible for a quarter of all human deaths worldwide.

The burden of EIDs is heavier in developing countries as compared to other parts of the world (Bownlie et al., 2005; Schoub, 2010). It is also believed that developing countries particularly those in Africa have the least capacity for the risk management of such diseases. Furthermore such capacity remains highly compartmentalised in professional silos based on operational health service delivery sector i.e. human, animals and plant as well as administrative boundaries (government, academic and private institutions) (Brownlie et al., 2005). Despite these challenges, African countries have tried to cope with the situation by developing own mechanism in dealing with EIDs.

This paper attempts to analyse the situation in Tanzania over 50 years of independence by reviewing the trend of occurrence of EIDs in human and animal populations. It also attempts to summarize efforts that have been made to cope with the situation through improving surveillance and response to EIDs after learning from past experiences.

* Correspondence: Esron D. Karimuribo; E-mail: esron.karimuribo@sacids.org 


\section{Materials and Methods}

\section{Data collection}

Data presented in this paper were obtained from extensive search of published and grey literature. Attempt was made to access published papers and unpublished reports related to infectious disease cases reported in human and animal (domestic and wildlife) over a period of 50 years. This involved physical visits of sources of data including the ministerial headquarters (Ministry of Health and Social Welfare-MoHSW and Ministry of Livestock and Fisheries Development-MoLFD). Review of available records and databases at the two ministries responsible for human (MoHSW) and animal (MoLFD) complemented literature review in summarizing and presenting data related to infectious disease epidemics in human and animal populations in Tanzania.

Attempts were also made to retrieve information related to endeavours made by both the MoHSW and MoLFD to improve surveillance, response and emergency preparedness for EIDs. Informal interviews with key informants responsible for surveillance and response were also carried out as part of validation of information obtained when analyzing emergency preparedness of Tanzanian human and animal health sectors to EIDs.

\section{Data management}

Data obtained were entered in Excel spreadsheet for future analysis and graphical presentation. Where necessary, information was summarized in tabular or graphical presentations as included in this paper. Content analysis of qualitative information collected by in-depth interviews or literature search was used to analyse and summarize information related to assessment of emergency preparedness to EIDs in Tanzania.

\section{Results}

\section{Occurrence of emerging and re-emerging diseases in the last five decades}

Zoonotic diseases: A number of zoonotic EIDs were introduced or re-introduced in Tanzania during the 50 years of independence (Table 1). Human plague re-emerged in Hai district of Kilimanjaro region in 1972 after 16 years of latency (Kilonzo, 1981). It is believed that the first human case of plague in Tanzania was reported in Iringa region in 1886 (Kamugisha et al., 2007). Human plague cases have been reported in more than 10 districts in nine regions of Tanzania during the 50 years of independence. The cases were reported in Kagera (Kagera district), Mara (Musoma district), Singida (Singida district) and Dodoma (Chamwino, Kondoa and Kongwa districts) (Msangi, 1968; Kilonzo, 1981; MoHSW 2009). Other regions reported cases of plague were Arusha (Arumeru and Ngorongoro districts) (Kilonzo et al., 2006), Manyara (Karatu and Mbulu districts) (Kilonzo and Mbise, 1998; Kilonzo et al., 2006), Kilimanjaro (Hai, Rombo and Same districts), Mwanza (Magu district) (MoHSW, 2009) and Tanga (Lushoto district) regions (Kamugisha et al., 2007; MoHSW 2009). Although no clinical cases of plague have been reported in domestic animals, the work by Kilonzo et al. (2006) suggests sylvatic plague to be endemic in some parts of Tanzania.

The recurrence of Rift Valley fever (RVF) in Tanzania is another example of an EID which had devastating impact on human and animal populations in Tanzania. Properly documented information on occurrence of RVF epidemics in Tanzania show that the disease has been recurring in ten-year cycles with three major epidemics reported in 1977, 1997/98 and 2006/2007 (Mohamed et al., 2010). Whereas RVF epidemics of 1977 and 1997/98 were largely confined to northern Tanzania, the 2006/2007 epidemic assumed a large scale with the disease being reported in 10 out of the 21 regions of Tanzania. Human cases were reported in Arusha, Dar es Salaam, Dodoma, Iringa, Manyara, Mwanza, Morogoro, Pwani, Singida and Tanga Regions. The occurrence of human cases were preceded by observation of suspected cases of abortion in 
domestic ruminants that were reported in Kilosa, Monduli, Ngorongoro, Simanjiro and Tarime districts between December 2006 and January 2007. The 2006/2007 RVF epidemic was classified as a national disaster thus its control involved inter-sectoral collaborations between human health, livestock health and local government authorities under the umbrella of the National Disaster Preparedness and Response unit within the Prime Minister's Office. Such collaborative efforts led to successful containment of the disease by May 2007 (Coker et al., 2011).The Ministry of Livestock Development declared RVF outbreak to had been brought under control on 18th June 2007.

Anthrax has been reported in humans, domestic and wild animals over several years in the country. Anthrax cases in humans have been reported in different parts of Tanzania (Webber 1985; Lembo et al., 2011). In most cases, human anthrax cases have been clinically manifested by sporadic, non-fatal cutaneous lesions in individuals who handled infected meat and milk. However, sometimes fatal cases associated with eating contaminated meat from infected animals have been reported. Fatal cases of anthrax have also been reported in domestic and wild animals. Anthrax outbreak in hippos was reported in Ugalla Game Reserve in 2000 and 2001 as well as in Mtera dam in 2003 (Kashaigili et al., 2005). Other wild animals, in which cases of anthrax have been reported, are wildebeest, buffalo, impala, giraffe, elephant, Grant's gazelle and Thomson's gazelle (Lembo et al., 2011). In wild carnivorous animals, anthrax caused deaths of cheetah and serval cat (Leptailurus serval) in Serengeti ecosystem (Lembo et al., 2011). Several large outbreaks (> 500 deaths) have been also been reported in cattle, goats and sheep in eastern part of the Serengeti National Park (Lembo et al., 2011).

Cases of rabies have been reported in different districts over the past 50 years. Human rabies cases were reported in the following districts: Dodoma (Mpwapwa district), Kagera (Biharamuro and Ngara districts), Kilimanjaro (Moshi rural district), Manyara (Babati and Hanang districts), Mara (Bunda, Musoma districts), Mbeya (Kyela, Mbozi and Rungwe districts), Mwanza (Geita, Kwimba, Misungwi, Mwanza City and Ukerewe districts), Shinyanga (Shinyanga district and Shinyanga municipality), Tabora (Nzega district) and Tanga (Kilindi, Korogwe and Muheza districts) (MoHSW, 2009). It is also worth noting that several cases of animals biting humans have been reported in all regions of Tanzania Mainland.

\section{Human diseases}

Different communicable diseases occurred or recurred in epidemic pattern in Tanzania over a period of 50 years post-independence. The most common conditions that were reported in human population included: Human Immunodeficiency virus/ Acquired Immunodeficiency Syndrome (HIV/AIDS), cholera, measles, meningitis, dengue fever and Influenza A H1N1 (swine flu).

Human Immunodeficiency virus infection was introduced in Tanzania and the first three cases of AIDS were reported at Ndolange hospital in Kagera region in 1983 (NACP, 2011). The infection spread very fast in the country and by 1999, all regions of Tanzania mainland had reported cases of HIV/AIDS. Efforts were made to control the infection under leadership of the National AIDS Control Programme (NACP) which was launched in 1985. The adult HIV/AIDS prevalence rate was recorded at highest peak during 2003 when it reached $8.8 \%$ and has since gradually declined to $5.6 \%$ in 2009 (ClA, 2011).

Repeated occurrence of cholera has been recorded in several years during the past 50 years. Major cholera epidemics and associated impact are summarized in Table 2. By year 2008, reported cases of cholera in the country had been reduced from 40,226 to 4,012 equivalent to more than $90 \%$ reduction in morbidity due to cholera in the country. The reduction in morbidity could be attributed to government intervention and increased public awareness on the disease. The disease has been commonly reported in Dar es Salaam, Dodoma, Kigoma, Rukwa, Lindi, Mara, Tanga and Iringa regions (Figure 1; Table 1). 
Another communicable disease that has been repeatedly reported to occur in epidemic pattern in Tanzania is measles. Tanzania first introduced measles vaccination programme in 1975 before which an average of 60,000 cases were reported in the country each year (Goodson et al., 2010). Although the vaccination programme significantly reduced morbidity and mortality attributed to measles in children, the disease has continued to be reported in different parts of the country. For instance, cases of measles were reported in Arusha, Pwani, Dodoma, Iringa, Kilimanjaro, Mara, Morogoro, Mwanza, Rukwa, Singida, Shinyanga and Mbeya regions in 19992001 period (Mnyika \& Akim, 2005). This study recorded a total number of 2,588 cases of measles with 38 deaths (case-fatality rate of 1.5\%). An outbreak of measles was reported in four Burundian refugee camps of Kanembwa, Karago, Mtendeli and Ndutain Kigoma region during 2000-2001 period (Kamugisha et al., 2003). It was believed the measles outbreak in refugee camps to be an extension of measles outbreak in Burundi which started in 1999. A large-scale outbreak of measles was also reported in Dar es Salaam city in 2006 (Goodson et al., 2010). The number of measles cases reported in different regions during 2008 year is shown in Figure 2. The picture indicates some regions such as Tabora, Rukwa and Mtwara to experience more cases than other regions. Overall, a total number of 5,962 cases of measles were reported in 2008 with 67 deaths (case-fatality rate of $1.1 \%$ ) recorded in the country.

Outbreak of rubella (German measles) was reported in Tanga city in 2011. Confirmation of this disease was possible through collaborative efforts between the Field Epidemiology and Laboratory Training Programme (FELTP) researcher and Tanga Regional Medical Office staff who carried out field investigation and confirmed the disease at Muhimbili Virology Reference Laboratory. Although the 2011 outbreak was the first one to be confirmed in Tanzania, previous work had reported either signs of rubella infection (Maselle et al., 1988) or signs compatible with congenital rubella syndrome (CRS) (Cutts et al., 1997)

During the period under review, Rooth \& Bjorkman (1992) reported outbreaks of influenza A, measles, and pertussis that had occurred in the Rufiji district of Tanzania during 19861987. During the same period, Masurel (1987) in Mwanza, tested sera from babies, young children and from mother-newborn pairs for $\mathrm{HI}$ antibody against influenza $\mathrm{A} \mathrm{H} \mathrm{H}_{1}, \mathrm{H}_{2} \mathrm{~N}_{2}, \mathrm{H}_{3} \mathrm{~N}_{2}$ viruses and found a high prevalence of antibody and high geometric mean titres against the A- $\mathrm{H}_{2} \mathrm{~N} 2-1957$ and A-H3N2-1968- viruses. 1992. In July 2009, Influenza A H1N1 (swine flu) was first reported in Tanzania. The first case was confirmed at Muhimbili National Hospital. The first death from Influenza A H1N1 was confirmed in Mbulu district in October 2009 when a 40-year primary school teacher died of swine flu (Z. Ubwani cited by IRIN on $12^{\text {th }}$ October 2009).

It was in February 2010 when Tanzania recorded the first outbreak of dengue fever in Dar es Salaam. By May 2010, about 100 cases of dengue fever were reported from hospitals in Dar es Salaam (Ministry of Health and Social Welfare, unpubl). 


\begin{tabular}{|c|c|c|c|}
\hline Disease & $\begin{array}{l}\text { Where and when first } \\
\text { observed/suspected }\end{array}$ & Who confirmed & Reference (s) \\
\hline \multicolumn{4}{|l|}{ A. Zoonotic diseases } \\
\hline Plague & \multirow{2}{*}{$\begin{array}{l}\text { Hai district in Kilimanjaro } \\
\text { Arusha, Manyara, Mara in } \\
1977,1997 / 98 \text { and } 2007\end{array}$} & \multirow{2}{*}{$\begin{array}{l}\text { - } \\
\text { RVF in human by CDC Kenya; Samples from animals by } \\
\text { Onderstepoort Veterinary Institute in South Africa }\end{array}$} & Kilonzo (1981) \\
\hline $\begin{array}{l}\text { Rift valley fever (in human and } \\
\text { livestock) }\end{array}$ & & & $\begin{array}{l}\text { FEWS NET (2007), Mohamed } \\
\text { et al. (2010) }\end{array}$ \\
\hline $\begin{array}{l}\text { Anthrax (in wild and domestic animals } \\
\text { and humans) }\end{array}$ & $\begin{array}{l}\text { Different parts over } \\
\text { several years }\end{array}$ & Local laboratory facilities & $\begin{array}{l}\text { Webber (1985), Prins \& } \\
\text { Weyerhaeuser } \quad(1987) \text {, } \\
\text { Mlengeya \& Mlengeya (2000) }\end{array}$ \\
\hline \multicolumn{4}{|l|}{ B. Exclusive human diseases } \\
\hline HIV/AIDS & \multicolumn{3}{|l|}{ Kagera region in 1983} \\
\hline Influenza A H1N1 & Dar es Salaam in 2009 & \multicolumn{2}{|l|}{ Muhimbili National Hospital, Dar es Salaam } \\
\hline Rubella & Tanga city in 2011 & Muhimbili Virology Reference Laboratory, Dar es Salaam & Shabani et al. (2011) \\
\hline Dengue fever & Dar es Salaam, 2010 & - & $\begin{array}{l}\text { Ministry of Health and Social } \\
\text { Welfare, unpubl }\end{array}$ \\
\hline \multicolumn{4}{|l|}{ C. Exclusive animal diseases } \\
\hline Contagious Bovine Pleuropneumonia & Ngorongoro in 1990 & Ministry of Livestock Development, Dar es Salaam & $\begin{array}{l}\text { Rweyemamu \& Benkirane } \\
\text { (1996) }\end{array}$ \\
\hline Contagious Caprine Pleuropneumonia & Arusha region in 1980 & National Veterinary Institute, Uppsala, Sweden & $\begin{array}{l}\text { Msami (1991), Kusiluka et al. } \\
\text { (2000) }\end{array}$ \\
\hline Peste des petits ruminants & Ngorongoro in 1995 & CIRAD, France & $\begin{array}{l}\text { Kivaria et al. (2009), Loomu } \\
\text { (2010), Karimuribo et al. } \\
\text { (2011a) }\end{array}$ \\
\hline Giraffe Ear Disease & $\begin{array}{l}\text { Mikumi National Park in } \\
1999\end{array}$ & - & $\begin{array}{l}\text { Mlengeya \& Lyaruu (2003), } \\
\text { Lyaruu (2009) }\end{array}$ \\
\hline Giraffe Skin Disease & $\begin{array}{l}\text { Ruaha National Park in } \\
2000\end{array}$ & - & Mpanduji et al. (2001) \\
\hline $\begin{array}{l}\text { Sexually Transmitted Disease in } \\
\text { baboons }\end{array}$ & $\begin{array}{l}\text { Manyara National Park in } \\
2003\end{array}$ & - & Mlengeya \& Lyaruu (2003) \\
\hline $\begin{array}{l}\text { Unexplained deaths of sitatunga and } \\
\text { bushbuck }\end{array}$ & $\begin{array}{l}\text { Rubondo Island National } \\
\text { Park }\end{array}$ & - & Mlengeya \& Lyaruu (2003) \\
\hline $\begin{array}{l}\text { Acute and fatal respiratory disease in } \\
\text { Chimpanzee }\end{array}$ & $\begin{array}{l}\text { Mahale National Park in } \\
2003\end{array}$ & $\begin{array}{l}\text { Virginia-Maryland Regional College of Veterinary } \\
\text { Medicine and CDC }\end{array}$ & Kaur1 et al. (2008) \\
\hline
\end{tabular}




\section{Table 2: Major cholera epidemics reported in Tanzania between 1990 and 2011 and their impact}

\begin{tabular}{|c|c|c|c|}
\hline When reported & Affected area & Impact & Reference \\
\hline Jun-Jul 1991 & Dar es Salaam and Bunda & $\begin{array}{l}12 \text { inmates at Ukonga prison died ( } 92 \text { cases reported); } 12 \text { patients died of cholera (52 cases } \\
\text { reported) at Kibara village in Bunda district }\end{array}$ & $\begin{array}{l}\text { Daily News of } 18^{\text {th }} \text { June } 1991 ; \mathrm{D} \\
\text { News of } 1^{\text {st }} \text { July } 1991\end{array}$ \\
\hline Apr 1992 & $\begin{array}{l}\text { Dodoma, Iringa, Dar es } \\
\text { Salaam, Singida and } \\
\text { Rukwa }\end{array}$ & $\begin{array}{l}\text { Overall, } 1,570 \text { cases reported in } 12 \text { weeks and } 275 \text { had died (case-fatality rate of } 17.5 \% \text { ). } \\
\text { Cholera was reported in Dar es Salaam ( } 118 \text { cases) where officials banned sale of unhygienic } \\
\text { local brews and food in the streets, in Rukwa ( } 904 \text { cases), in Iringa ( } 50 \text { patients died), in } \\
\text { Singida ( } 8 \text { patients admitted at Manyoni district hospital, } 3 \text { died) and in Dodoma ( } 16 \text { people } \\
\text { died). }\end{array}$ & Kenya Times of $6^{\text {th }}$ April 1992 \\
\hline Jun - Dec 1997 & Ifakara & $\begin{array}{l}785 \text { patients admitted at the Ifakara cholera treatment sites. Case-fatality rate of } 2.1 \% \text { was } \\
\text { reported. }\end{array}$ & Acosta et al. (2001) \\
\hline Jan-Dec 1997 & Different parts & $\begin{array}{l}\text { A total number of } 40,226 \text { cases were reported in Tanzania during } 1997 \text { with case-fatality } \\
\text { rate recorded at } 5.6 \% \text { (i.e. } 2,268 \text { deaths) }\end{array}$ & WHO (1998) \\
\hline Aug 2007 & Mara region & $\begin{array}{l}\text { Ten people died of cholera and } 20 \text { admitted to various health facilities in Mara region. } \\
\text { Disease prevention campaign launched focusing on educating communities on the } \\
\text { importance of boiling water, use toilets and washing hands after visiting toilets and before } \\
\text { eating. }\end{array}$ & IRIN (2007) \\
\hline Jan-Dec 2008 & Different parts & A total number of 4,012 cases were reported with case-fatality rate of $0.5 \%$ & MoHSW (2009) \\
\hline Oct 2009 & Handeni district & $\begin{array}{l}\text { A total number of } 511 \text { cases and } 12 \text { deaths were reported in Handeni district. The district } \\
\text { authorities closed all primary schools to avoid further transmission of the infection in the } \\
\text { district. }\end{array}$ & IRIN (2009) \\
\hline Dec 2010 & Different parts & $\begin{array}{l}\text { At least } 87 \text { patients were admitted following outbreak of cholera in Dar es Salaam, Tanga } \\
\text { and Shinyanga }\end{array}$ & The Citizen of $2^{\text {nd }}$ December 20 \\
\hline Aug 2011 & Lindi & $\begin{array}{l}\text { Cholera outbreak was reported in Lindi in July } 2011 \text { where } 219 \text { cases were reported in } \\
\text { Nyangao, Mtama, Kilimahewa, Mtua and Mahumbika villages. A total number of } 12 \text { deaths } \\
\text { due to cholera were reported. }\end{array}$ & The Guardian of $18^{\text {th }}$ July 2011 \\
\hline
\end{tabular}




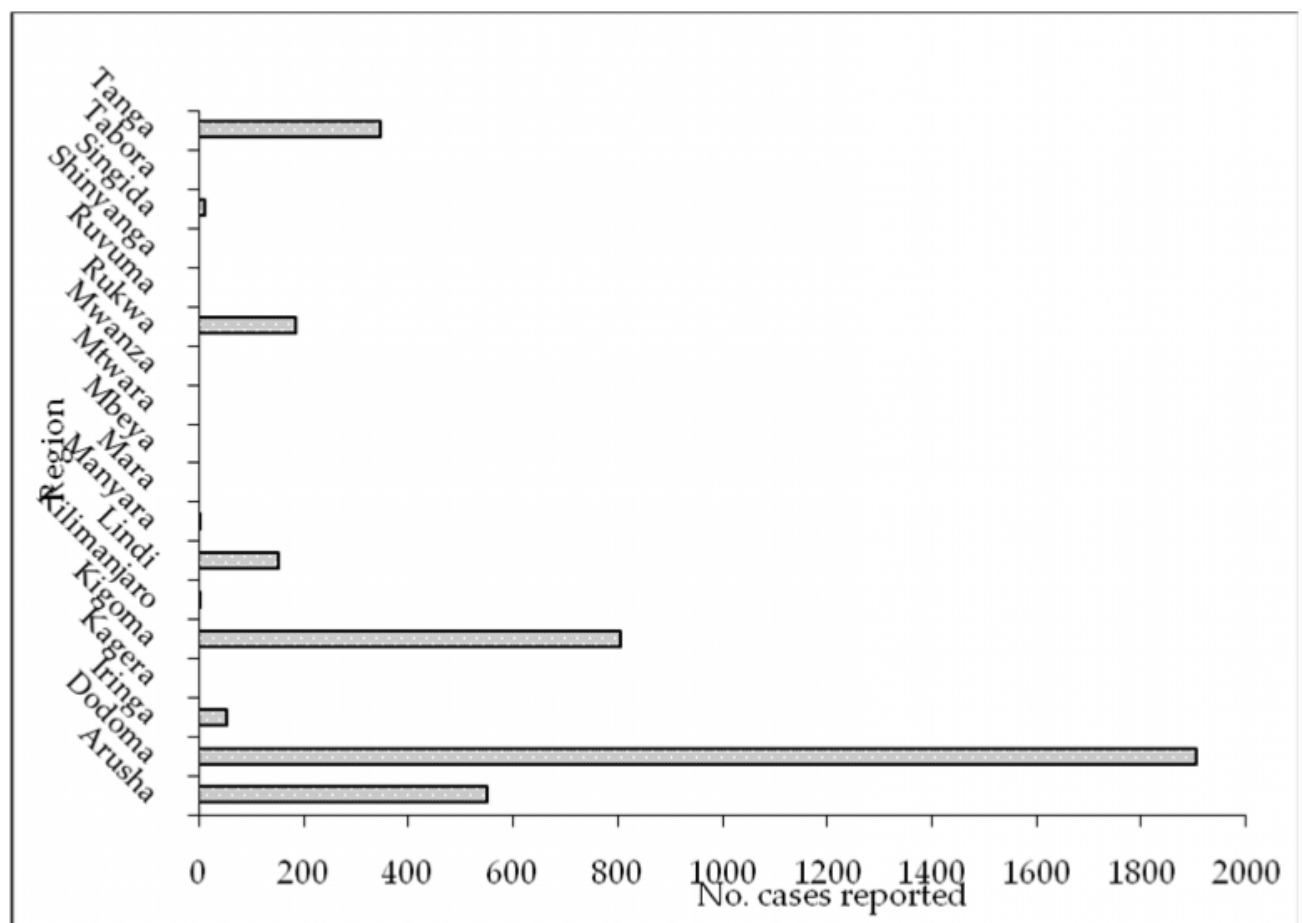

Figure 1: Number of cholera cases reported by regions ${ }^{\dagger}$ in 2008 (Source: MoHSW, 2009)

${ }^{\dagger}$ Cholera cases for Dar es Salaam, Morogoro and Pwani regions were missing thus not included

\section{Animal diseases}

Outbreaks of diseases which exclusively affect animals (both domestic and wildlife) were reported in Tanzania between 1961 and 2011 (Table 1). Documented literature shows that Contagious Bovine Pleuropneumonia (CBPP) was first introduced in Tanzania in Loliondo area of Ngorongoro district of Arusha region in 1916 (Msami et al., 2001). The disease was eradicated in the country in 1964 and re-introduced in the same area in 1990 (Kusiluka \& Sudi, 2003). The disease spread so fast and has been reported in 54 districts and 19 regions as of 2005 (MoLFD, 2011).

Introduction of yet another devastating disease of goats and sheep called Contagious Caprine Pleuropneumonia (CCPP) in Tanzania was suspected in 1980 and officially confirmed in 1998 (Msami, 1991; Msami et al., 1998). Since then, CCPP has spread widely throughout the country causing tremendous losses in the goat industry. In pastoral and non-pastoral areas of Tanzania, outbreaks of CCPP are reported frequently but the disease remains largely uncontained using conventional methods (Kusiluka et al., 2007).

Peste des petits ruminants (PPR), another fatal disease affecting goats and sheep was officially confirmed to had been introduced in Tanzania in 2008 (Kivaria et al., 2009). The disease was believed to have been spread from Kenya. A retrospective sero-epidemiological study carried out recently found that PPR-suspected animals were seropositive since 1995 (Karimuribo et al., 2011a). A study by Epaphras et al. (2011) further confirmed PPR to had reached southern part of Tanzania in Tandahimba and Newala districts in 2010. If the disease is allowed to spread from Tanzania into the whole of the 15-nation Southern African Development Community it could potentially devastate the livelihoods and food security of millions of small herders and agropastoralists. 


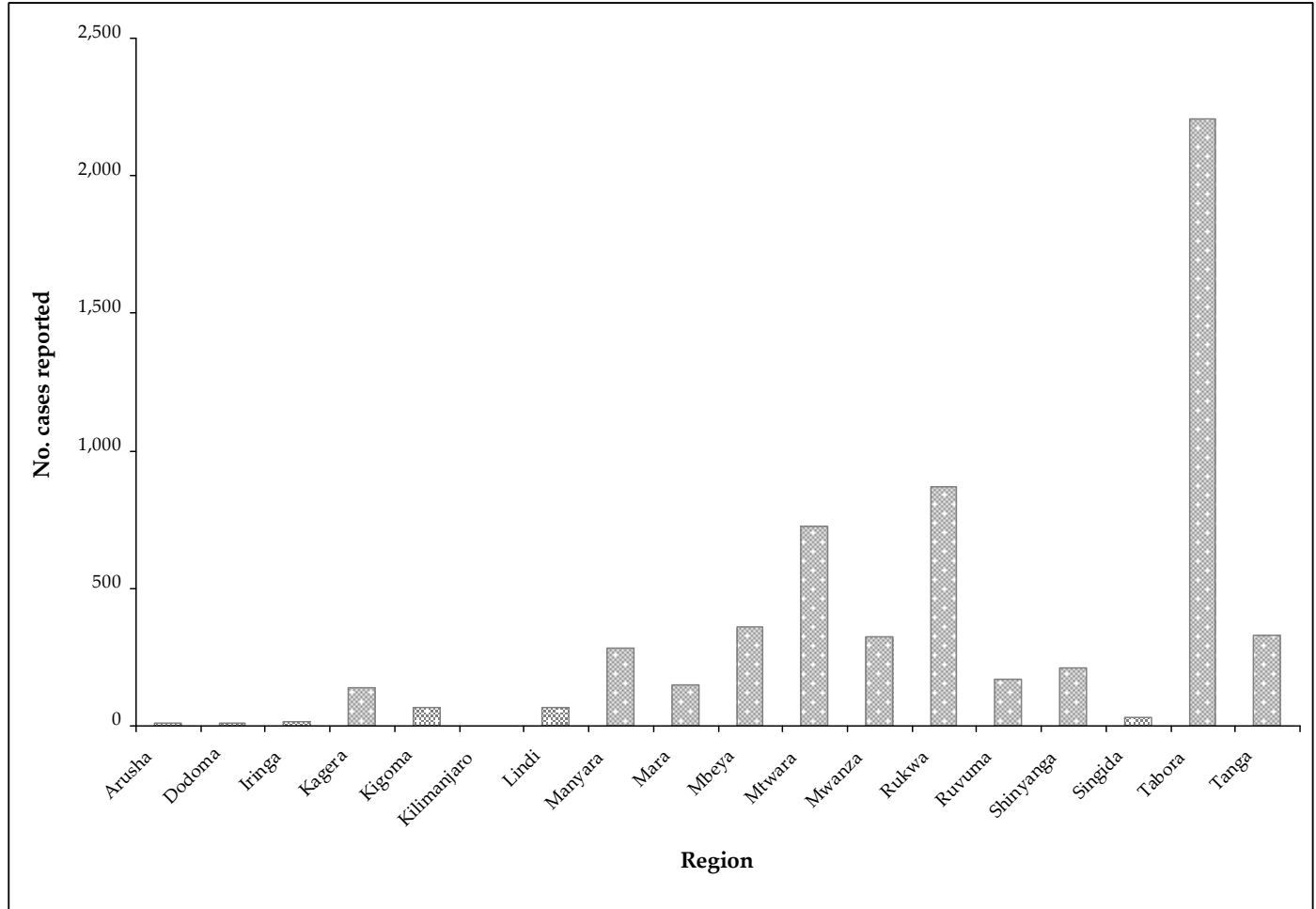

Figure 2: Number of measles cases reported by regions ${ }^{\dagger}$ in 2008 (Source: MoHSW, 2009)

${ }^{\dagger}$ Measles cases for Dar es Salaam, Morogoro and Pwani regions were missing thus not included

Recurrence of rinderpest during 50 years of independence was preceded by implementation of control measures during pre-independence period which involved control of animal movements, quarantine and vaccination of cattle using Kabete attenuated goat vaccine. It is believed that rinderpest was first observed in the country in 1891 (MoWLD, 2002). Through annual vaccination campaigns, rinderpest was almost under control in Tanganyika in 1953. Measures taken during post-independence period focused on control and disease surveillance under the Joint Project (JP) 15 when tissue culture vaccine was used. Fewer disease outbreaks were noted in 1961 (4 outbreaks), 1965 (1 outbreak) and 1966 (1 outbreak). In 1980s, rinderpest outbreak was reported in wild animals in Serengeti National Park when deaths of 2,000 were reported (MoWLD, 2002). This was followed by another outbreak in 1982-1983 in Mkomazi Game Reserve where massive deaths of buffaloes, kudus and elands were reported. The Ministry of Livestock Development launched strategic annual vaccination campaigns in 1982. The last rinderpest cases were reported in Hai district in 1997. Tanzania decided to follow OIE pathway towards eradication of the disease. In July 1998, Tanzania declared herself free from rinderpest and applied for OIE recognition of freedom from the disease. In October 2002, the Directorate of Veterinary Services of the then Ministry of Water and Livestock Development launched a Rinderpest Emergency Preparedness Plan which led to declaration of freedom from rinderpest by OIE.

The occurrence of Giraffe Ear Disease (GED), Giraffe Skin Disease (GSD), sexually transmitted disease in baboons and fatal respiratory condition in chimpanzee are some examples of EIDs that were reported in wild animals in Tanzania (Mlengeya \& Lyaruu, 2003; Lyaruu, 2009) (Table 1). Initial investigations of GED and GSD suggest involvement of nematodes although confirmation of aetiology and pathogenesis of these two diseases is not yet known (Lyaruu 2009; Mpanduji et al., 2011). Unexplained deaths of sitatunga and bushbucks in Rubondo Islands is another challenge facing the Tanzania National Parks veterinary department. In 2003, a study by Kaur1 et al. (2008) identified a human-related Metapneumovirus to be responsible for 
acute and fatal respiratory illness which occurred in outbreaks in 2003, 2005 and 2006. Other infectious disease outbreaks that were reported in wild animals are anthrax, brucellosis and rabies (Mlengeya \& Mlengeya, 2000).

\section{Aetiologies of EIDs emerged or re-emerged in the past 50 years}

Grouping of causative agents for EIDs which emerged or re-emerged in the countries indicated that the majority of these conditions were viral (RVF, HIV/AIDS, Influenza A H1N1, Dengue fever, PPR and Acute Respiratory Disease of Chimpanzee) followed by bacterial diseases (Plague, Anthrax, CBPP and CCPP) (Figure 3). Twenty five per cent of the EIDs had unknown aetiologies and all of them were reported in the wildlife animals.

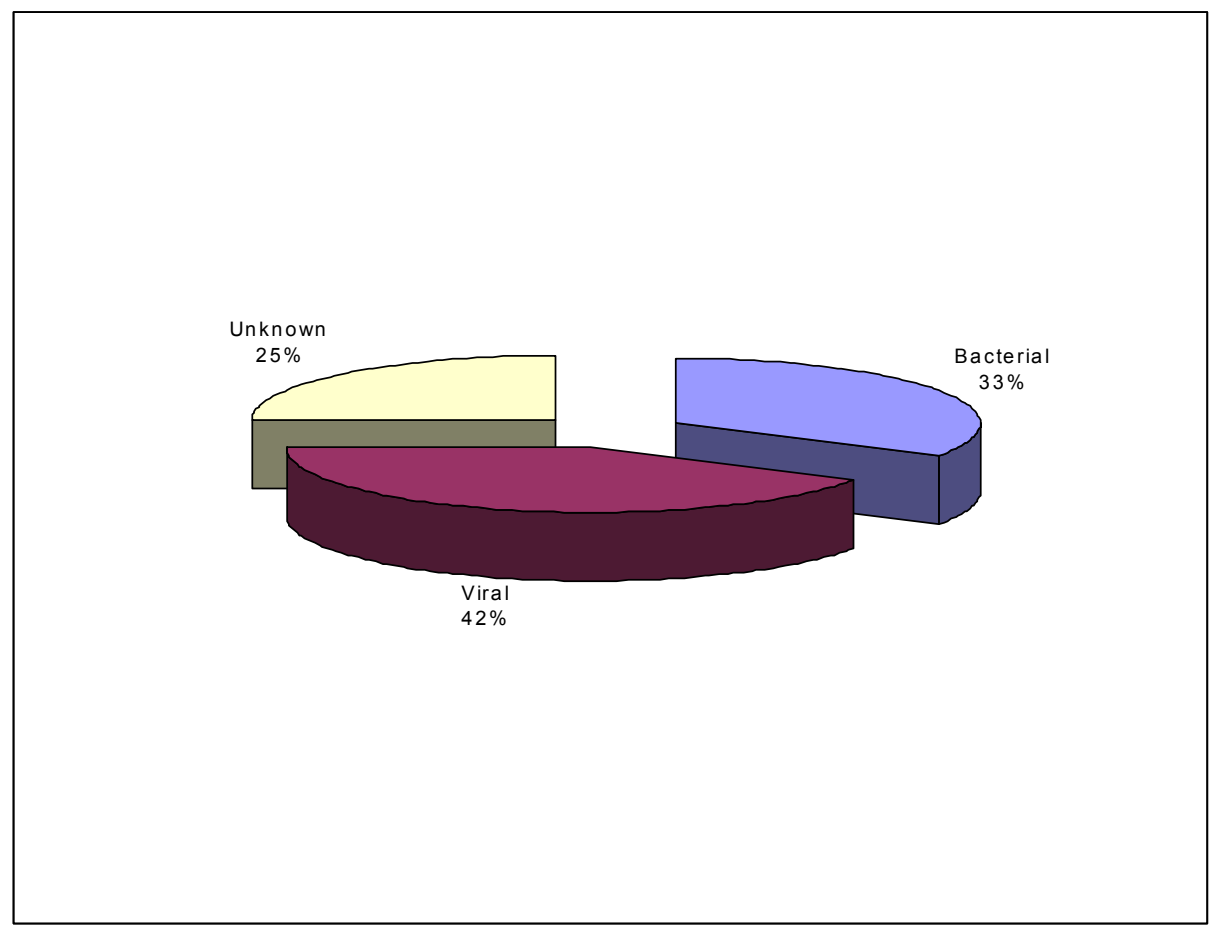

Figure 3: Distribution of aetiologies for 12 diseases emerged or re-emerged in Tanzania during the past 50 years

\section{Emergency Preparedness to combat EIDs in Tanzania}

\section{Facilities and institutions for managing EIDs}

Over time, Tanzania has improved facilities and institutions responsible for management of EIDs. Endeavours to improve disease surveillance and response in Tanzania resulted into introduction of Health Management Information System between 1993 and 1997 by the Ministry of Health (Mboera et al., 2001). In 2001, the Ministry of Health introduced the Integrated Disease Surveillance and Response Strategy (IDSR) strategy. The two systems capture disease events recorded at public and private health facilities in the country. In 1999, the Ministry of Livestock Development introduced Transboundary Animal Disease Information-TADinfo) software to handle epidemiological data on animal disease surveillance (FAO, 2011). The software is used to analyse and map data collected using field and abattoir report disease surveillance forms. The Ministry of Livestock Development also introduced the Digital Pen Technology (DPT) in pilot districts to enhance transmission of disease surveillance data. Following realisation of risk associated with EIDs, the MoHSW established the Emergency and Disaster Preparedness Unit 
(EPRU) in 2008. The EPRU collaborates with the Disaster Management Department under the Prime Minister's Office and with other stakeholders including the MoLFD (MoHSW, 2010).

Policy and legal frameworks were also established or improved to cater for managing EIDs in the country during the past 50 years. The first National Health Policy was formulated in 1990 which originated from the Arusha Declaration of 1967 (Dominicus \& Akamatsu, 1989). The MoHSW revised the National Health Policy which was approved in 2007 (MoHSW, 2010). The Health Policy, among other things, emphasises on importance of preventing and controlling communicable diseases, especially diseases from outside the country (exotic EIDs. The Public Health Act was enacted in 2009 (URT, 2011). In the animal health sector, various policy and legal documents have also been formulated. They include The Agriculture and Livestock Policy 1997, The Animal Diseases Act 2003 and The Veterinary Act 2003.

\section{'One Health' approach in preventing and controlling EIDs in Tanzania}

After realizing the importance of 'One Health' concept, Tanzanian institutions have progressively inclined towards adopting the concept in controlling EIDs. A number of national and regional consortia and networks have emerged. These include, but are not limited to, the Southern African Centre for Infectious Diseases (SACIDS), One Health Central and Eastern Africa (OHCEA), Afrique One to mention a few. A number of academic and research institutions have or are planning to mainstream the 'One Health' concept in their training programmes. For instance, MSc in One Health Molecular Biology has been launched by Sokoine University of Agriculture in 2011 and the MoHSW launched the Field Epidemiology and Laboratory Training Program (FELTP) in 2008 which started with the Epidemiology and Laboratory tracks (DGPHCD, 2009). There are plans to introduce a Veterinary Track in the FELTP in Tanzania in order to recognize the role of veterinary professionals in public health. This approach has already been adopted in Nigerian FELTP program. The Nelson Mandela African Institute of Science and Technology (NM-AIST) is also planning to launch a One Health course.

\section{Discussion}

The paper has attempted to review the situation of EIDs in humans and animal populations over a period of 50 years post-independence. The number of cases and outbreaks of various diseases presented in this paper is considered lower than actual events that occurred in the country. This is partly attributed to lack of systematic capturing and recording of all disease events particularly during early years post-independence due to limited number of human resources, equipment and technologies. It is expected that improvement of disease surveillance strategies and availability of better tools and technologies will significantly contribute to improved recording of events in future. This is supported by recent emergence of disciplines and technologies with the potential of enhancing efficiency of disease surveillance and response. Such disciplines include participatory epidemiology and disease surveillance, risk based disease surveillance and use of nanotechnology in diagnosing diseases at point of care. Application of mobile technologies such as phone for health (P4H), Digital Pen and Paper technology (DPT) and use of Android phones powered by Epicollect are some of those technologies that are expected to enhance disease surveillance (Aanensen et al., 2009; Karimuribo et al., 2011b). Application of nanotechnology in disease diagnosis involves use of materials, devices and systems at the nanometer scale which in turn helps, through miniaturisation of screening assays, to reduce volume and the use of expensive reagents in rapid disease diagnosis at point of care (Jain, 2005; Sahoo et al., 2007).

Overall, the ministries responsible for human and animal health in Tanzania have tried their best to improve surveillance and response to EIDs. Records of successful control and eradication of some diseases such as the RVF, Influenza A $\mathrm{H}_{1} \mathrm{~N} 1$ and rinderpest are good examples of such commendable efforts realised in the country. 
A number of EIDs are still menace to the country such as cholera, measles, rubella, CBPP, CCPP and PPR. Although legal and policy frameworks have been developed, failure to control or eradicate some of these conditions is partly attributed to inadequate implementation of such measures. Collaborative efforts between all stakeholders in controlling and eradicating the diseases are needed if the country target to improve health and welfare of human and animal populations in Tanzania. Although it was beyond scope of this paper to analyse impact and losses attributable to EIDs in the country, it is no doubt that these conditions have significantly contributed to enormous losses as indicated by deaths, failure to engage in productive activities and resources committed in controlling disease outbreaks when they occur. It has been noted that occurrence of some diseases like cholera has at times impacted on people's livelihood such as ban on selling food and drinks and closure of schools in some areas of the country.

Occurrence of disease outbreaks in the wildlife sector in the recent past poses challenges in controlling or preventing such diseases. So far, the aetiologies of the majority of wildlife disease outbreaks observed between 1990 s and 2000 s are unknown. This calls for investing in research and improving diagnostic capabilities of our local laboratories in the country. Adoption of 'One Health' approach in sharing information and resources could be the most economically feasible way of addressing major issues related to identification, monitoring and management of EIDs in human, domestic and wild animal populations.

\section{Acknowledgements}

We acknowledge the assistance received from various individuals at the Ministry of Health and Social Welfare and the Ministry of Livestock and Fisheries Development during data collection. We thank Dr Hezron E. Nonga for assisting retrieval of some published work while in Norway. Part of information included in this paper was obtained through a rapid situation analysis carried out under a research project supported by the Rockefeller Foundation, project 2008 DSN 310.

\section{References}

Aanensen, D.M., Huntley, D.M., Feil, E.J., al-Own, F. \& Spratt, B.G. (2009) EpiCollect: Linking smartphones to web applications for epidemiology, ecology and community data collection. PLOS ONE 4 (9): e6968. doi:10.1371/journal.pone.0006968.

Acosta, C.J., Galindo, C.M., Kimario, J., Senkoro, K., Urassa, H., Casals, C., Corachán, M., Eseko, N., Tanner, M., Mshinda, H., Lwilla, F., Vila, J. \& Alonso, P.L. (2001) Cholera outbreak in Southern Tanzania: Risk factors and patterns of transmission. Emerging Infectious Diseases 7, 583-587.

Brownlie, J., Morgan, D., Otim-Nape, W., Rweyemamu, M., Serwadda, D. \& Waage, J. (2005) Infectious diseases in Africa: Using science to fight the evolving threat. Report of a PanAfrican Workshop held in Entebbe, Uganda, August 2005. Foresight, Office of Science and Technology. London.

CIA (2011) The World Factbook: Tanzania. Central Intelligence Agency.

Coker, R., Rushton, J., Mounier-Jack, S., Karimuribo, E., Lutumba, P., Kambarage, D., Pfeiffer, D., Stärk, K. \& Rweyemamu, M. (2011) Towards a conceptual framework to support 'One Health' research and policy. Lancet Infectious Diseases. doi: 10.1016/S1473-3099(10)70312-1.

Cutts, F.T., Robertson, S.E, Diaz-Ortega, J-L. \& Samuel, R. (1997) Control of rubella and congenital rubella syndrome (CRS) in developing countries, part 1: burden of disease from CRS. Bulletin of the World Organization 75, 55-68.

DGPHCD (2009) Tanzania Field Epidemiology and Laboratory Training Program. Division of Global Public Health Capacity Development CDC, USA. Available at http://www.cdc.gov/globalhealth/FETP/pdf/Tanzania_factsheet_508.pdf 
Dominicus, D.A. \& Akamatsu, T. (1989) Health policy and implementation in Tanzania. Keio Journal of Medicine 38, 192-200.

Epaphras, A.M., Karimuribo, E.D., Gitao, G.C., Misinzo, G., Mellau, L.S.B., Msoffe, P.L.M, Swai, E.S., \& Albano, M.O. (2011) Epidemiological investigation of introduction and factors for spread of peste des petits ruminants in the southern Tanzania. Onderstepoort Journal of Veterinary Research (In press).

FAO (2011) Animal Disease Information system: TADinfo. In: EMPRESS Transboundary Animal Diseases Bulletin. Issue No. 19. Food and Agriculture Organization. Available at www.fao.org

FEWS NET (2007) Tanzania Food security watch: Rift Valley fever in Northern Tanzania threatens pastoral recovery. Farming Early Warning Systems Network. Unpublished report.

Goodson, J.L., Perry, R.T., Mach, O., Manyanga, D., Luman, E.T., Kitambi, M., Kibona, M., Wiesen, E. \& Cairns, K.L. (2010) Measles outbreak in Tanzania, 2006-2007.Vaccine 28, 5979-5985.

Jain, K.K. (2005). Nanotechnology in clinical laboratory diagnostics. Clinica Chimica Acta 358, 3754.

Kamugisha, C., Cairns, K.L. \& Akim, C. (2003) An outbreak of measles in Tanzanian refugee camps. Journal of Infectious Diseases 187 (Suppl 1), S58-62.

Kamugisha, M.L., Gesase, s., Minja, D., Mgema, S., Mlwilo, T.D., Mayala, B.K., Msingwa, S., Massaga, J.J. \& Lemnge, M.M. (2007) Pattern and spatial distribution of plague in Lushoto, northern Tanzania. Tanzania Health Research Bulletin 9, 12-18.

Karimuribo, E.D., Loomu, P.M., Mellau, L.S.B. \& Swai, E.S. (2011a) Retrospective study on seroepidemiology of peste des petits ruminants before its official confirmation in northern Tanzania in 2008. Research Opinions in Animal and Veterinary Sciences 1, 184-187.

Karimuribo, E.D., Sayalel, K., Beda, E., Short, N., Wambura, P., Mboera, L.E.G., Kusiluka, L.J.M. \& Rweyemamu, M.M. (2011b) Towards one health disease surveillance: the Southern African Centre for Infectious Disease Surveillance (SACIDS) approach. Onderstepoort Journal of Veterinary Research (In press).

Kashaigili, J.J., Kadigi, R.M.J., Lankford, B.A., Mahoo, H.F. \& Mashauri, D.A. (2005) Environmental flows allocation in river basins: Exploring allocation challenges and options in the Great Ruaha river catchment in Tanzania. Physics and Chemistry of the Earth 30, 689-697.

Kaur1, T., Singh, J.,Tong, S., Humphrey, C., Clevenger, D.,Tan, W.,Szekely, B., Wang, Y., Li, Y., Muse, E.A., Kiyono, M., Hanamura, S., Inoue, E., Nakamura, M., Huffman, M.A., Jiang, B. \& Nishida, T. (2008) Descriptive epidemiology of fatal respiratory outbreaks and detection of a human-related Metapneumovirus in wild chimpanzees (Pan troglodytes) at Mahale Mountains National Park, Western Tanzania. American Journal of Primatology 70, 1-11.

Kilonzo, B.S. \& Mbise, T.J. (1998) Plague survey at Karatu, Arusha in August 1998. Unpulished report submitted to the Ministry of Health, Dar es Salaam.

Kilonzo, B.S. (1981) The origin, dissemination and present status of plague in Tanzania. Dar es Salaam Medical Journal 8, 130-142.

Kilonzo, B.S., Mbise, T.J., Mwalimu, D.C. \& Kindamba, L. (2006) Observations on the endemicity of plague in Karatu and Ngorongoro, northern Tanzania. Tanzania Health Research Bulletin $8,1-6$.

King, D.A., Peckham, C., Waage, J.K., Brownlie, J. \& Woolhouse, M.E.J. (2006) Infectious diseases: Preparing for the future. Science 313, 1392-1393.

Kivaria, F.M., Kwiatek, O, Kapaga, A.M., Libeau, G., Mpelumbe-Ngeleja, C.A.R.,Tinuga D.K. (2009) Serological and virological investigations on an emerging peste des petitsruminants virus infection in goats and sheep in Tanzania. A paper presented at the $27^{\text {th }}$ Tanzania Veterinary Association Scientific Conference, AICC, Arusha, Tanzania.

Kusiluka, L.J.M. \& Sudi, F.F. (2003) Review of successes and failures of contagious bovine pleuropneumonia control strategies in Tanzania. Preventive Veterinary Medicine 59, 113123. 
Kusiluka, L.J.M., Kimaryo, S.J., Nsengwa, G., Kazwala, R.R. \& Kambarage, D.M. (2007) Serological and microbiological studies of Contagious Caprine Pleuropneumonia in selected districts of Tanzania. Bulletin of Animal Health and Production in Africa 55, 88-95.

Kusiluka, L.M.J., Semuguruka, W.D., Kazwala, R.R., Ojeniy, B. \& Friis, N.F. (2000) Demonstration of Mycoplasma capricolumsubspcapripneumoniae and Mycoplasmamycoides subsp mycoides small colony type outbreaks of caprine pleuropneumonia in Eastern Tanzania. Acta Veterinaria Scandinavica 41, 311-319.

Lembo, T., Hampson, K., Auty, H., Beesley, C.A., Bessell, P., Packer, C., Halliday, J., Fyumagwa, R., Hoare, R., Ernest, E., Mentzel, C., Mlengeya, T., Stamey, K., Wilkins, P.P. \& Cleaveland, S. (2011) Serologic surveillance of anthrax in the Serengeti ecosystem, Tanzania, 1996-2009. Emerging Infectious Diseases. http://dx.doi.org/10.3201/eid1703.101290 店

Loomu, P.M. (2010) Transboundary animal disease surveillance in Ngorongoro district: The case of peste des petits ruminants. A research paper submitted for the Master of Preventive Veterinary Medicine (MPVM) degree at Sokoine University of Agriculture.

Lyaruu, V. (2009) Epidemiological study of Giraffe Ear Disease in Mikumi National Park. PhD thesis. Sokoine University of Agriculture.

Maselle, S.Y., Haukenes, G. \& Rutahindurwa, A. (1988) Preliminary observations on rubella infection in Tanzania and the challenge for its control. East African Medical Journal 65, 319324.

Masurel, N. (1987) Influenza A and B antibody status in Tanzania. Transactions of the Royal Society of Tropical Medicine and Hygiene 81, 75-79.

Mboera, L.E.G., Rumisha, S.F., Magesa, S.M. \& Kitua, A.Y. (2001) Utilisation of Health Management Information in Disease Surveillance in Tanzania. Tanzania Health Research Bulletin 3 (2), 15-18.

Mlengeya, T. \& Lyaruu, V. (2003) Experiences and challenges of wildlife health management in National Parks of Tanzania.IUCN 2003 World Parks Congress AHEAD Launch forum. Available at http://www.wcs-ahead.org/abstracts/ab_mlengeya.html

Mlengeya, T. \& Mlengeya, M. (2000) Wildife health status in national parks of Tanzania: 19962000. In: Proceedings of the $18^{\text {th }}$ Scientific Conference of the Tanzania Veterinary Association held at AICC, Arusha on $5^{\text {th }}$ to $7^{\text {th }}$ December 2000. pp 215-229.

Mnyika, K.S. \& Akim, C. (2005) Epidemiology of measles in Tanzania: A hospital-based survey of measles morbidity and mortality. East African Journal of Public Health 2, 24-27.

Mohamed, M., Mosha, F., Mghamba, J., Zaki, S.R., Shieh, W-J., Paweska, J., Omulo, S., Gikundi, S., Mmbuji, P., Bloland, P., Zeidner,N., Kalinga, R., Breiman, R.F. \& Njenga, M.K. (2010) Epidemiologic and clinical aspects of a Rift Valley fever outbreak in humans in Tanzania, 2007. American Journal of Tropical Medicine and Hygiene 83, 22-27.

MoHSW (2009) Annual Health Statistical Tables and Figures 2009. Ministry of Health and Social Welfare, Dar es Salaam. Unpublished report.

MoHSW (2010) Health Sector Strategic Plan III July 2009-June 2015. Ministry of Health and Social Welfare, Dar es Salaam. Unpublished report.

MoLFD (2011) Transboundary Animal Diseases. Ministry of Livestock and Fisheries Development Dar es Salaam. Unpublished report. Available at http://www.mifugo.go.tz/documents_storage/tads.pdf

Morse, S.S. (1995) Factors in the emergence of infectious diseases. Emerging Infectious Diseases 1, 7-15.

MoWLD (2002) Rinderpest Emergency Preparedness Plan for Tanzania. Ministry of Water and Livestock Development, Dar es Salaam. Unpublished report.

Mpanduji, D.G., Karimuribo, E. \& Epaphras, A.M. (2011) Investigation of Giraffe Skin Disease of Ruaha National Park, Southern Highlands of Tanzania. A report submitted to Tanzania National Parks (TANAPA). Unpublished. 
Msami H.M., Kapaga A.M., Bolske G.,. Kimaro R.T., Mundogo J. \& Mbise A. (1998) Occurrence of Contagious Caprine Pleuropneumonia in Tanzania. Proceedings of the 16th Scientific Conference of the Tanzanian Veterinary Association, Arusha, Tanzania,3-5 December, pp: 4348.

Msami, H.M. (1991) Pneumonia in goats in Tanzania with special regards to mycoplasma infection. In: Proceedings of the $9^{\text {th }}$ Scientific Conference of the Tanzania Veterinary Association, Arusha.

Msami, H.M., Ponela-Mlelwa T., Mtei B.J. \& Kapaga, A.M. (2001). Contagious Bovine Pleuropneumonia in Tanzania: Current Status. Tropical Animal Health and Production 33, 21-28.

Msangi, A.S. (1968) Observations on the Endemicity of Plague in Tanzania. PhD thesis, University of Dar es Salaam.

NACP (2011) HIV/AIDS in Tanzania. , National AIDS Control Programme. Available at http://www.nacp.go.tz

Prins, H.H. \& Weyerhaeuser, F.J. (1987) Epidemics in populations of wild ruminants: anthrax and impala, rinderpest and buffalo in Lake Manyara National Park, Tanzania. Oikos 49, 28-38.

Rooth, I. \& Bjorkman, A. (1992) Fever episodes in a holoendemic malaria area of Tanzania: parasitological and clinical findings and diagnostic aspects related to malaria. Transactions of the Royal Society of Tropical Medicine and Hygiene 86, 479-482.

Rweyemamu, M.M. \& Benkirane, A. (1996) Global impact of infections with organisms of the "Mycoplasma mycoides cluster" in ruminants. In: Agriculture and Biotechnology Mycoplasmas of ruminants: pathogenicity, diagnosis, epidemiology and molecular genetics. Edited by Frey, J. and Sarris, K. European Commission Report EUR 16934 EN pp 1-11.

Sahoo, S.K., Parveen, S. \& Panda, J.J. (2007) The present and future of nanotechnology in human health care. Nanomedicine: Nanotechnology, Biology and Medicine 3, 20-31.

Schoub, B.D. (2010) Surveillance and management of influenza on the African continent. Expert Review of Respiratory Medicine 4, 167-169.

Shabani, S.S., Urio, L., Simba, A., Mohamed, A., Semali, I., Mghamba, J. \& Mmbuji, P. (2011) Rubella outbreak in Tanga city, Tanzania. EAIDSNet Bulletin 1 (3), 1-8.

URT (2011) The Public Health Act. Parliament of the United Republic of Tanzania. Available at www.parliament.go.tz/bunge/acts.php

Webber, R.H. (1985) Anthrax in Lake Rukwa Valley, Tanzania: a persistent problem. Journal of Tropical Medicine and Hygiene 88, 327-331.

WHO (1998) Cholera in 1997. Weekly Epidemiological Record 73, 201-208. 